\title{
Comparative Advertising: Proposed Guidelines for Middle Marketers
}

\author{
Bassant Eyada ${ }^{1} \&$ Asli Cazorla Milla ${ }^{2}$ \\ ${ }^{1}$ Faculty of Mass Communications, Ahram Canadian University, Giza, Egypt \\ ${ }^{2}$ College of Business Administration, American University in the Emirates, Dubai, United Arab Emirates \\ Correspondence: Asli Cazorla Milla, Dubai International Academic City, Block 6-7, COBA-AUE, Dubai, United \\ Arab Emirates. E-mail: asli.milla@aue.ae
}

$\begin{array}{lc}\text { Received: March 9, 2020 } & \text { Accepted: April 15, } 2020 \quad \text { Online Published: April 17, } 2020 \\ \text { doi:10.5539/ijms.v12n2p23 } & \text { URL: https://doi.org/10.5539/ijms.v12n2p23 }\end{array}$

\begin{abstract}
This article presents a review of comparative advertising from a theoretical perspective and uses a combination of literature review and content analysis as a research methodology. The main objective of the article is to propose a legislative framework for marketers in the Middle East for using comparative advertising. Advertising plays a significant role in promoting and marketing products and brands. Comparative advertising affects consumer behaviour, decision making and consumerism following the ethical standards of advertising which control the form of competition between products which affects the brand image and the relation between consumers and the products. While competition between brands becomes hostile in some cases, the purpose of competitive or comparative advertising is to compare the entity of a product to the entity of its competitor on the basis of one or more product characteristics, as part of an advertising campaign. Known to have two different types: direct and indirect, where the name of the competitor is specifically mentioned, and superiority is established over them within the direct form, as for the indirect the product places superiority over its competitors without explicitly mentioning the name, which is widely seen in the Middle East advertising campaigns. This research aims to study the ethical standards of comparative advertising, implications of direct comparative advertising on consumer behaviour through content analysis of comparative ads to set guidelines for using other product's name or trademark in advertising within the Middle East. The lack of availability of the empirical data on comparative advertising in the Middle Easts presents both a challenge and an opportunity for academicians. The paper concludes with the notion that comparative advertising is an effective way to attract consumers, and it is recommended to be used in the Middle East with the proposed guidelines.
\end{abstract}

Keywords: comparative advertising, advertising law, advertising ethics, consumer behavior, Middle East

\section{Introduction}

Comparative advertising has been rapidly growing over the past decades, considered to be one of the highly effective advertising strategies used, where one brand claims superiority over its competitor. Having two different forms, direct and indirect, the direct comparative advertising names the competing brand and compares itself to characteristics, benefits or market positioning. Whereas, indirect comparative advertising does not state the name of the competitor, referring to it as a leading brand or brand $\mathrm{X}$, sometimes appearing in a blurred vision without revealing the brand name. The vital aim of comparative advertising is to change consumers perception of one product relative to the competitor, found to elicit higher levels of consumer-message involvement and processing, that is due to the amount of information being provided within these ads than noncomparative ones.

The existence of comparative advertising is widely seen in the U.S. for several products; the most commonly known for example are Advil Vs Tylenol, Pepsi Vs Coca Cola, Mcdonalds Vs Burger King, Quizno's Vs Subway and more. Throughout the twentieth century, the U.S. had been fighting comparative advertising stating that it has become quite aggressive, created problems and raised concerns about being potentially misleading to the consumers. It was in 1971 when the Federal Trade Commission began legitimizing the use of comparative advertising, stating that these comparisons improve the quality of the advertising industry, as it provides useful price and performance information, and helps consumers positively evaluate the competitive options of products. The American Association of Advertising Agencies had also recognized comparative advertising as a correct and fair form of advertising which provides the consumer with useful facts and information, yet, to be used with extreme caution in order not to misrepresent the truth. 
The purpose of this research is to study the ethical standards of comparative advertising with previous examples and then propose a guideline for the Middle East marketers. Direct comparative advertising has not been observed in the Middle East, and no clear legislation is set concerning this form of advertising. However, indirect advertising plays a huge role in the advertising strategies established for the Middle East. Products refer to their competitors using blurred images where the brand name is not mentioned. On the other hand, direct comparative advertising is not permitted in many countries. The study aims to answer the following questions:

1) Is there a guideline/legislation for adopting comparative advertising in the Middle East countries?

2) How Middle East legislations for comparative advertising should differ from the rest of the world?

\section{Literature Review}

\subsection{Definition and Evolution of Comparative Advertising}

Comparative advertising is a persuasive advertising strategy meant to communicate verbally and visually the competitive advantage of superior brands in the market, being termed as contrast ads, negative ads, attack ads or knocking copy (Moore, 1999). Where they identify the competitor to claim superiority or to enhance consumer perception of the advertised product. Comparative advertising appears in two different types, direct and indirect, where direct comparative ads clearly name the competitor and compares to similar attributes, market positions and benefits. Whereas indirect comparative ads refer to competitors by "brand $\mathrm{x}$ " without mentioning the brand name.

The history of comparative advertising goes back more than a decade ago, starting in the US, the legality of honest comparative advertising was welcomed and recognized. It began in the 1960s by brands referring to their competitors as "brand X" under the impression that mentioning the competitor's name would only provide the competitor with more publicity, no other benefit was seen at that time. It was until the significant decision of the Federal Trade Commission (FTC) in 1969, where comparative advertising was encouraged especially by mentioning the competitor's name, considering it a valuable source of information for the consumers, considering it an efficient marketing tool that enhances innovation and improvement among brands. Throughout the 1970s, comparative advertising was not actively used in the US until early 1979 when FTC vigorously lobbied for it.

Carl Ally Incorporate founded in the US in 1962, later known in 1977 as "Ally and Gargano" was leading the comparative advertising industry in the US, starting with the Volvo TV commercial, see Figure 1, where the car was seen outpacing five recognizable competitors. Hertz was the second brand to head for comparative advertising.
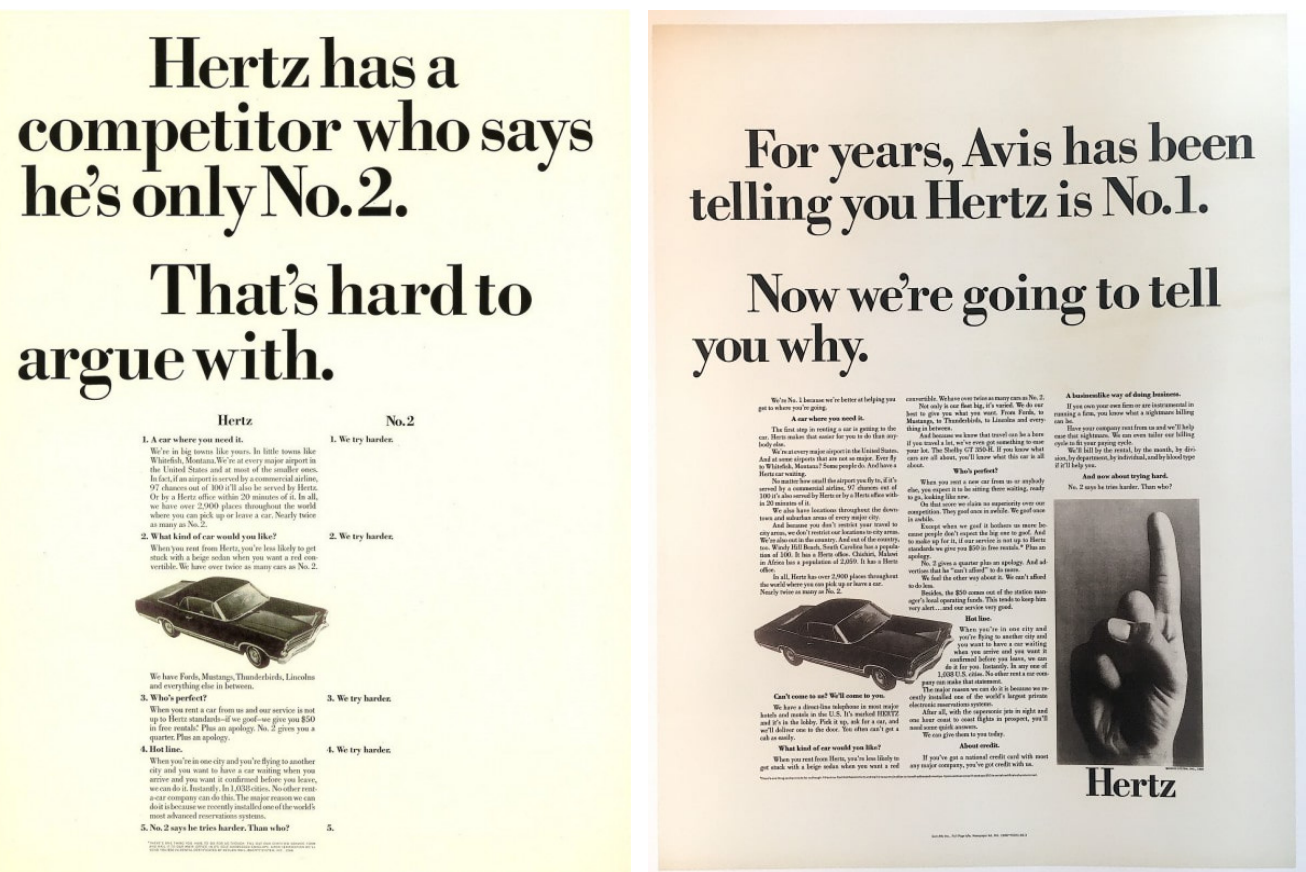

Figure 1. Hertz ad competing against Avis, showing why Avis is number two in the business 
Several brands headed towards comparative advertising, Fiat along with Carl Ally leads towards comparative advertising by publishing a print ad in 1971 in Playboy Magazine, the ad tops Fiat over Volkswagen, Renault and Volvo with a comparison of sales (see Figure 2). FedEx again being a client of Carl Ally, led their comparative ads against Emery Air Freight Corporation, and decided to do its research to prove which company is better, by filling 47 packages with sand and shipped them by both companies. Later on, it was translated through a print ad in 1980 with the headline "If you're using Emery, you'd better not let your boss see these figures" (see Figure 3).

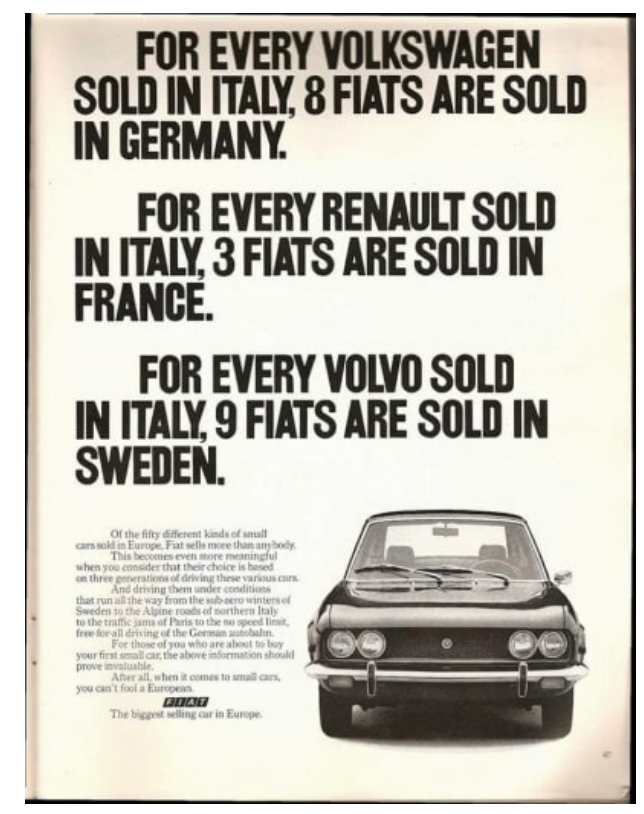

Figure 2. Fiat comparative ads, showing superiority over Volkswagen, Renault and Volvo

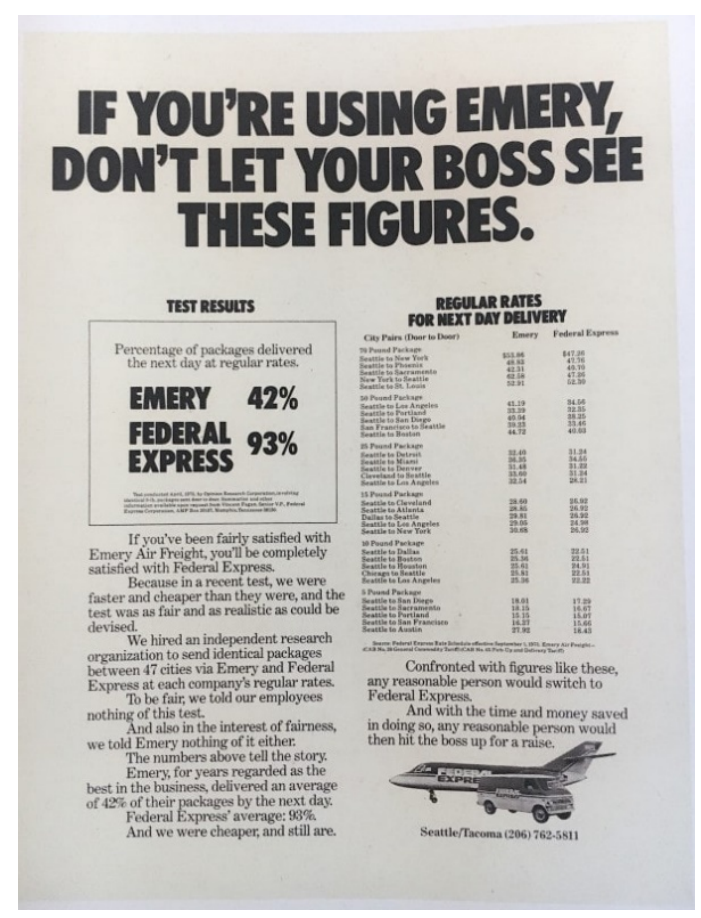

Figure 3. FedEx Vs Emery comparative ad 


\subsection{Types of Comparative Advertising}

\subsubsection{Direct and Indirect Comparative Advertising}

Indirect comparative advertising creates a comparison between a product and other competitive products without mentioning their specific names. For example, a product states that it cleans better than other products, or is the least expensive, or performs better than other competitors, which is widely seen in the MENA region advertising.

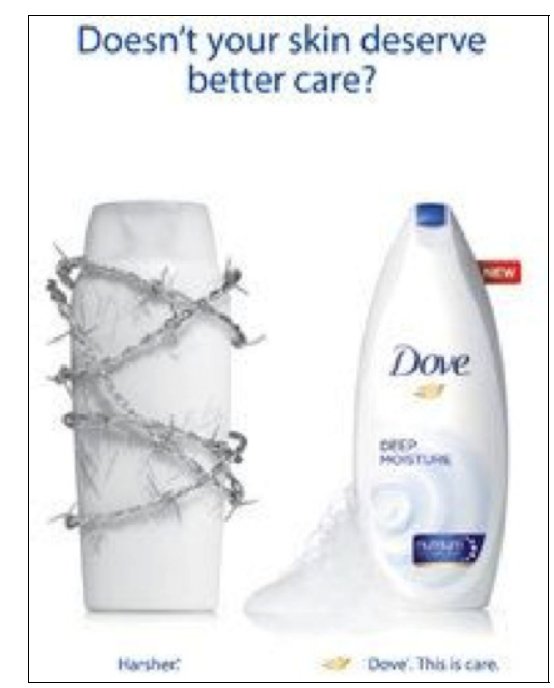

Figure 4. Dove indirect comparative ad

When we look at Dove's ad in Figure 4, we see that they are trying to show the consumers that their moisturizer is than its competitors. While the competitor's name is not mentioned, the bottle with spikes represents Dove's competitor for in the market.

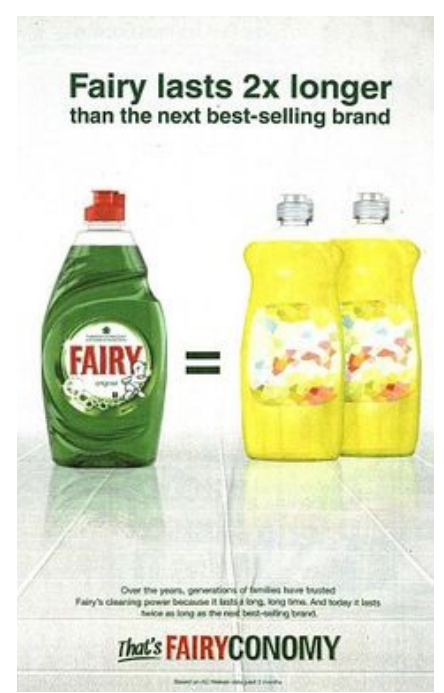

Figure 5. Fairy indirect comparative ad

In this ad, Fairy states that it lasts twice as long as its competitor, although mentioning that its competitor is the next best-selling brand, no specific name was mentioned.

In direct comparative advertising, the product states the name of the competitor precisely or uses specific ideas, icons, figures, or incidents related explicitly to its competitor to create a side-by-side comparison showing superiority. Direct comparative ads are also differentiated by whether they are positive or negative. Positive 
comparative advertising usually acknowledges that the competitor has certain valuable features, but states that it has better or extra features which the competitor does not have. Negative comparative advertising plays on a weak feature which the competitor has, whether it is quality or price, without acknowledging any positive features, the advertised product shows superiority by not having those poor features of the competitor. Apple products have had a series of negative comparative ads against Android systems, and Microsoft, comparing iPhones to Samsung, and Mac to Microsoft Computers. Both brands created a series of advertisements which can be observed in Figure 6.
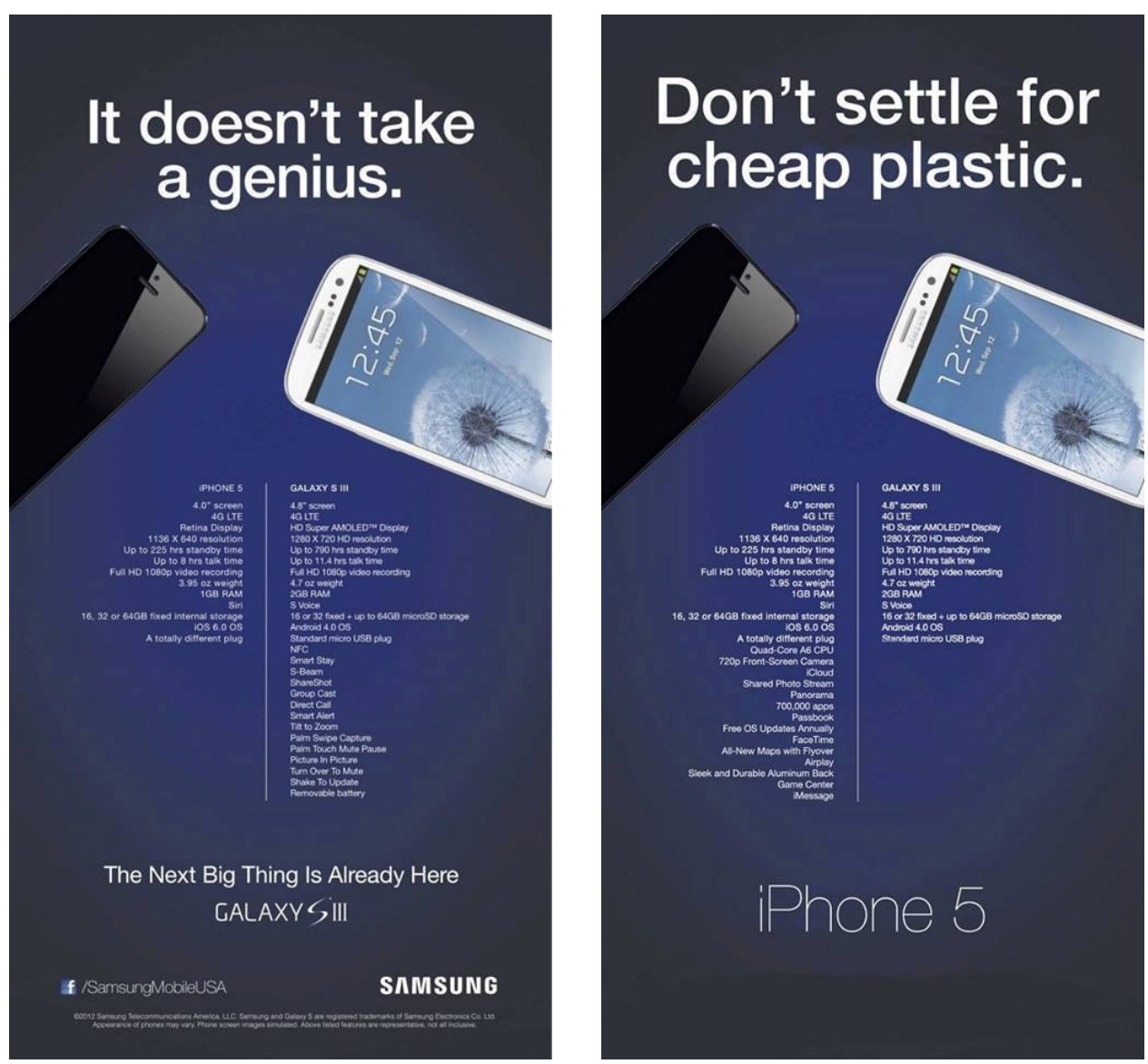

Figure 6. Samsung vs iPhone

The first ad shows Samsung's superiority over iPhone, stating and comparing the features of both phones, having Samsung with a longer list of features saying that it does not take a genius to realize the difference. Accordingly, Apple replies back with an ad that shows more features of its iPhone, using the exact same design, outline and colours, with a headline that degrades the quality of plastic used in the manufacturing of Samsung mobile phones. 


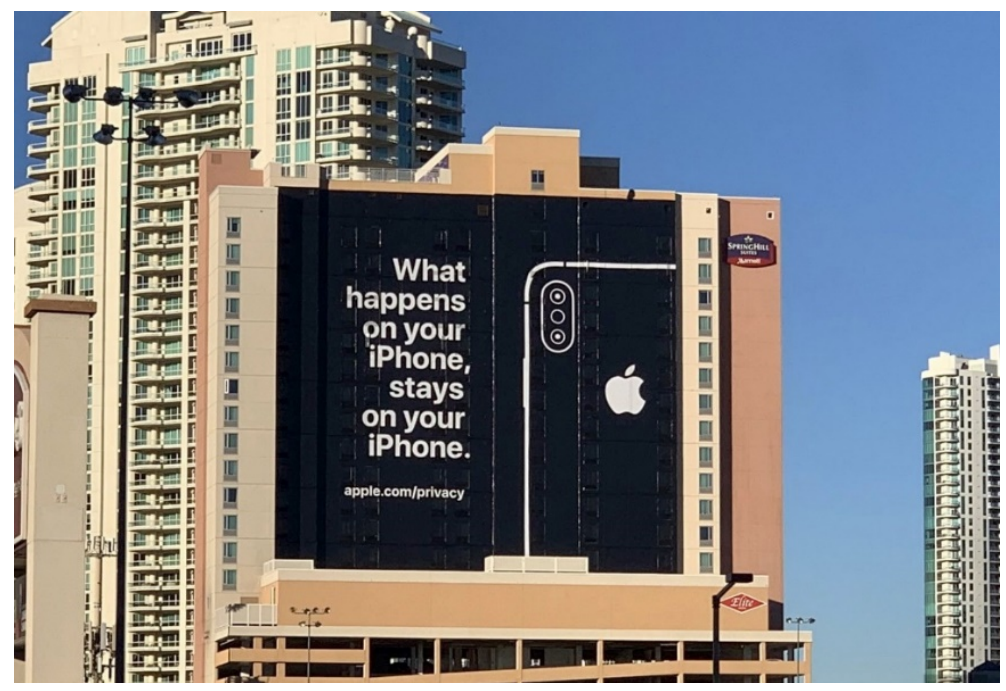

Figure 7. iPhone vs Samsung

In 2019, Apple took massive advertising space in Las Vegas, see Figure 7, to highlight its privacy policies, playing against Android and Google-operated systems which leak user's data. Although the competitors' name is not mentioned, it is yet unmistakably comprehended by the consumers Android being iPhone's competitor.

Burger King is known to be using indirect comparative ads widely to show superiority over its main competitor McDonald's. As seen in the above ad in Figure 8, the McDonalds well-known clown appears ordering food from Burger King; without specifically mentioning the competitors' name but using the well-recognized figure of Burger Kings' competitor.

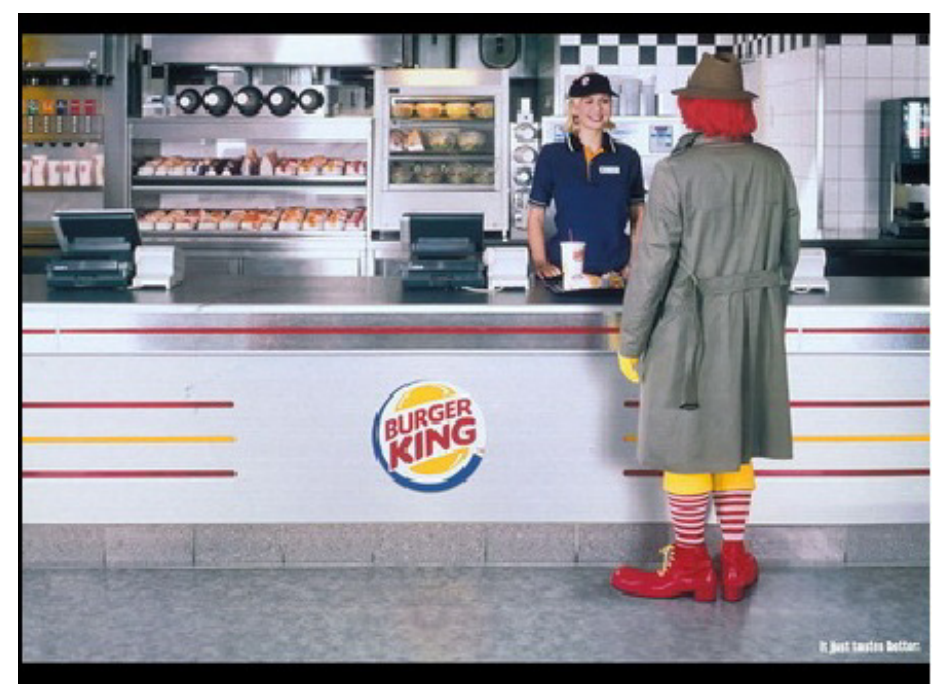

Figure 8. Burger King vs McDonalds comparative ad

Again, seen in this ad in Figure 9 we observe that how Burger King compares itself to McDonald's, showing the superiority of the size of its burger which does not fit into the box of the known Big Mac of McDonald's. Again, the name of McDonald's itself is not specifically mentioned, but consumers cannot mistake the Big Mac. 


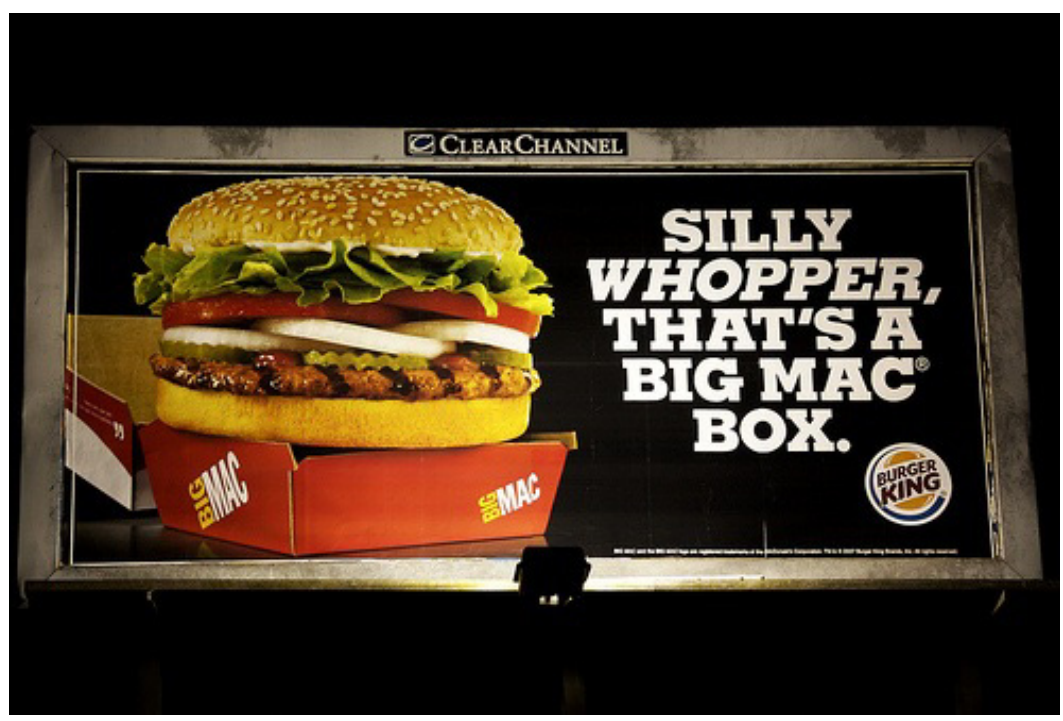

Figure 9. Burger King vs McDonalds comparative ad

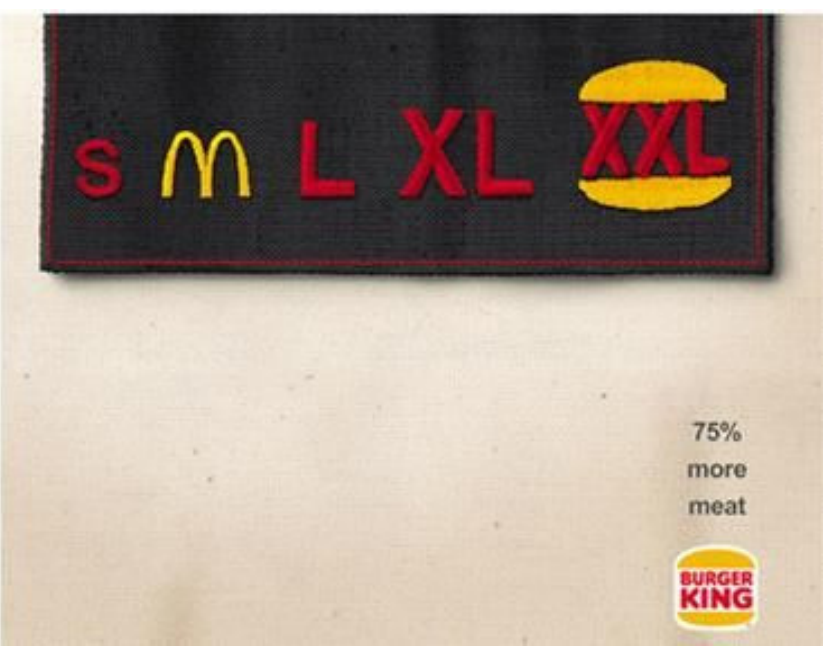

Figure 10. Burger King vs McDonalds comparative ad

In Figure 10, the superiority of Burger King's burger size is being seen by using the logo of McDonald's to represent the word "medium". In contrast, Burger King's burger is seen as XXL.

Audi and BMW have been known to use a series of non-stop comparative advertising billboards. It all started when BMW had released an ad campaign for the 35th MOA Rally Chess Tournament in California in 2007, using the ambush marketing tactic to promote the tournament (see Figure 11). The ad war started when Audi placed a large billboard replying to the BMW ad with the headline "Chess? No Thanks, I'd Rather be Driving", where BMW had to take the next move (see Figure 12). 


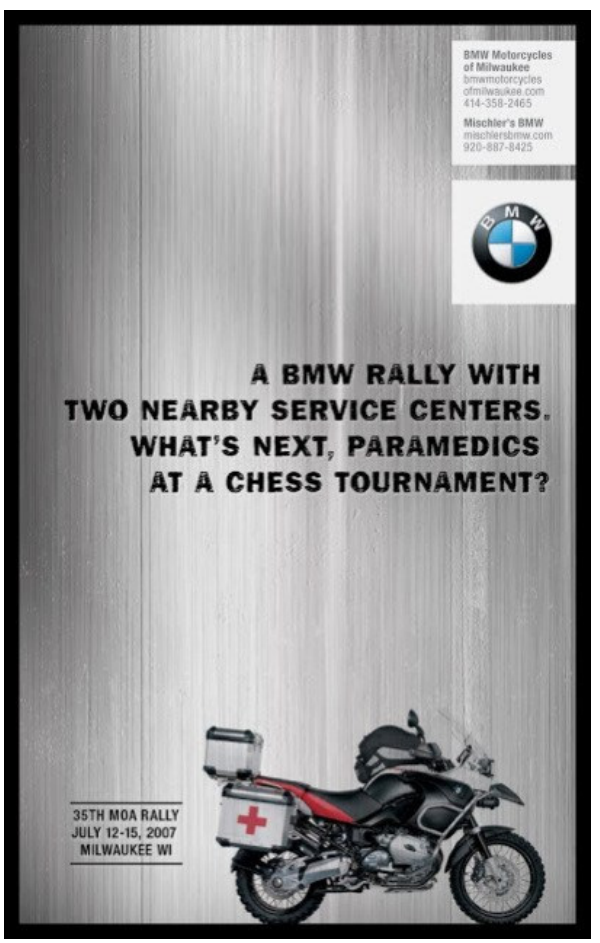

Figure 11. The BMW rally ad

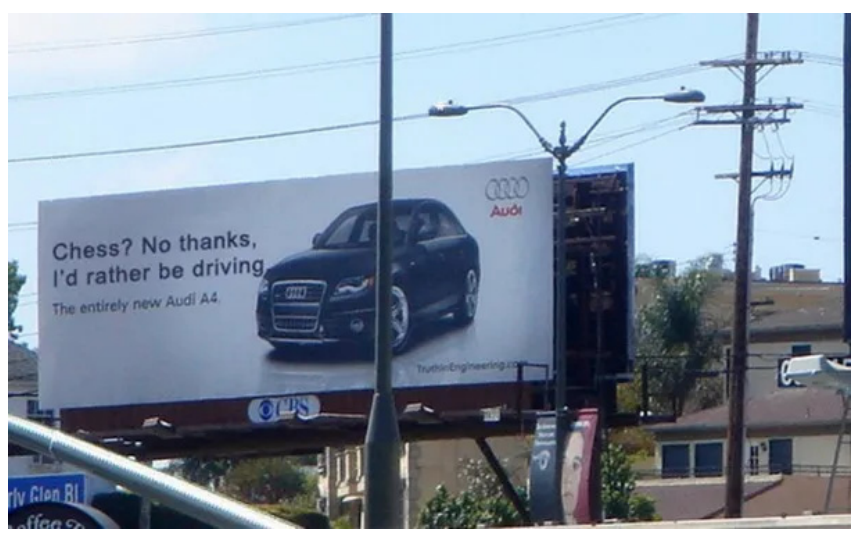

Figure 12. Audi billboard replying to BMW

Audi, later on, changes the message of its billboard ad directly pointing at BMW with the headline "Your Move, BMW". BMW then places a billboard three times the size of Audi's ad with the message "Checkmate" (see Figure 13). 


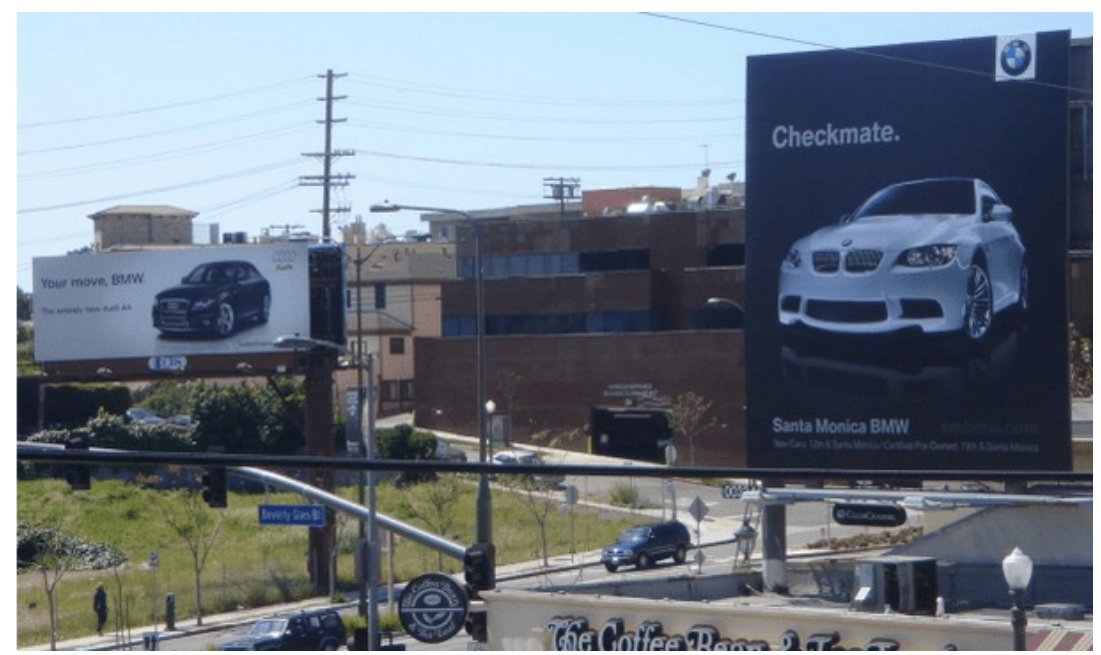

Figure 13. BMW billboard replying to Audi

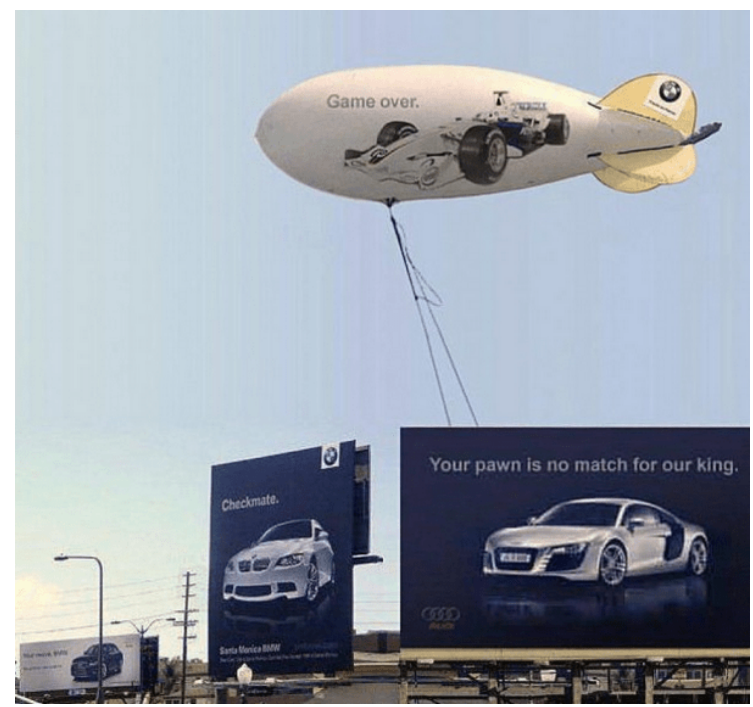

Figure 14. BMW vs Audi

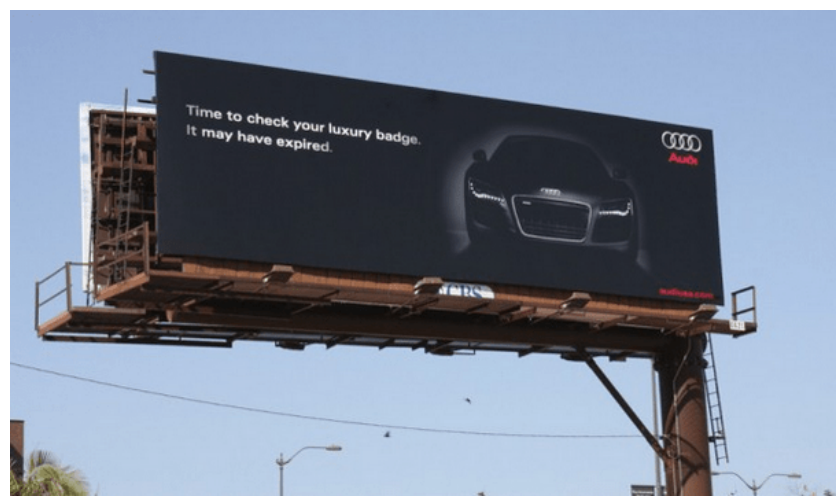

Figure 15. Audi replies to BMW ad

The ad war between Audi and BMW did not stop, as Audi replies with another message stating "Your pawn is no match for our king" (see Figure 14). Lastly, BMW places a huge blimp tethered above Audi's billboard stating "Game Over". Audi then takes the final stand by placing a billboard on reply to this stating "Time to check your luxury badge. It may have expired" (see Figure 15). 
Competition between the two brands did continue, using the direct positive comparative ads, Audi sarcastically congratulates BMW for winning World Car of the Year 2006, and BMW replies (see Figures 16 and 17).

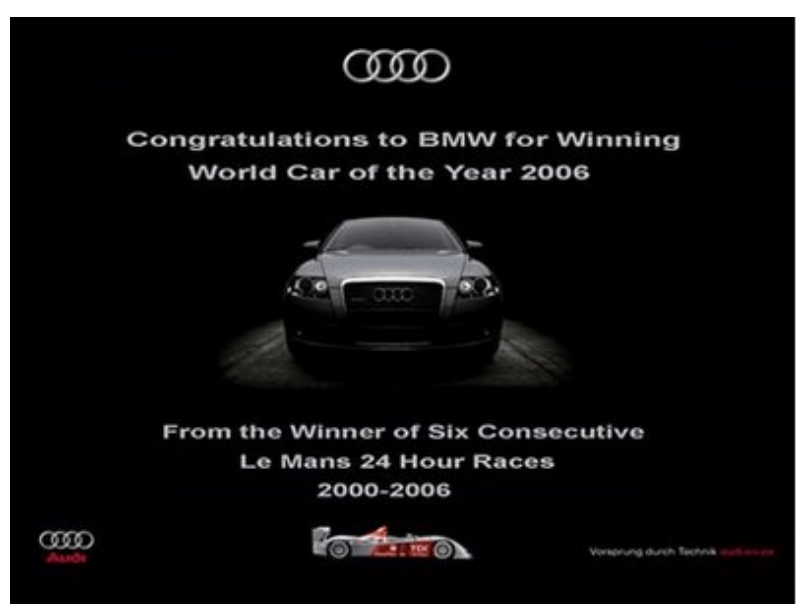

Figure 16. Audi congratulates BMW on winning World Car of 2006, while showing superiority by winning six consecutive races of 2004-2006

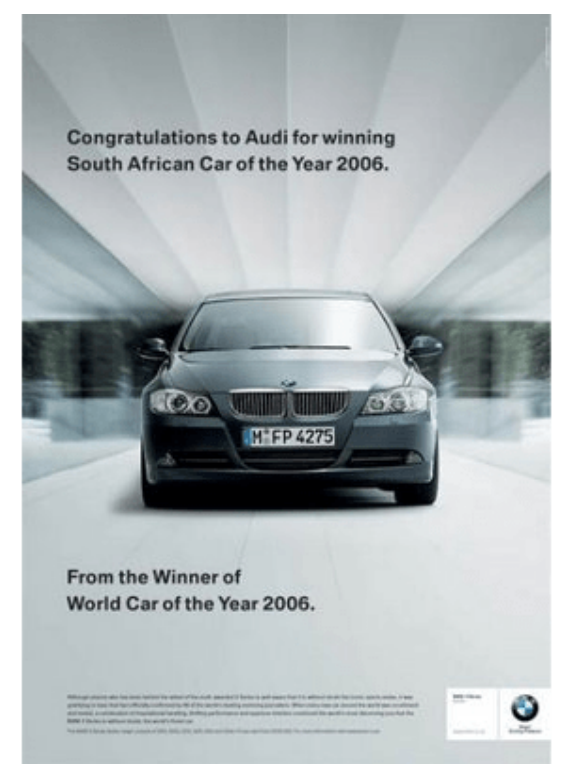

Figure 17. BMW replies by congrating Audi for winning South African Car 2006, showing superiority of winning World Car 2006

\subsection{Forms of Comparative Advertising}

Comparative advertising is considered a marketing strategy where the product is being presented as a superior to its' competitor, based on two aspects: a side-by-side comparison of features, or based on value and cost. As stated in the FTC statement of policy regarding comparative advertising: "Comparative advertising is defined as advertising that compares alternative brands on objectively measurable attributes or price and identifies the alternative brand by name, illustration or other distinctive information". Where comparison may be direct or indirect having a positive or negative tone, comparative advertising may not always work as intended, as it may act as free advertising for the competitor especially if the difference between products is of no significance.

\subsection{Effectiveness of Comparative Advertising}

While comparative advertising is a proven marketing tactic, due to the increased clutter in the digital media, it becomes harder to stand out by merely attacking the competitor. It is vital to get the facts right before attacking to competitor. Back in 2012, Microsoft Bing attacked Google with "Don't get Scroogled" campaign heavily (See 
Figure 18. However, the results were not valid because their claims of privacy were not proven to be true. Consumers claim that they do not prefer negative ads; however, their effect is determined to be the opposite. In the past, we have seen that most small companies go after the big and established brands. However, recently this seems to be the old way of executing the ads. Small brands also use comparative advertising to showcase their message and attack big giants. Companies need to find their voice and try to keep the comparison light in order not to be in danger of getting sued. Harmon et al. emphasized that the objective of comparative advertising is to change consumers' impressions of the advertised brand in comparison with the competitive brand. Therefore, similar ads must have a higher level of message involvement and processing activity compared to other ads. (Harmon et al., 1983)

Beard assessed the effect of comparative advertising and found that the potential for adverse outcomes is a genuine possibility when prominent brands choose to go head to head using strictly comparative advertising campaigns (Beard, 2010).

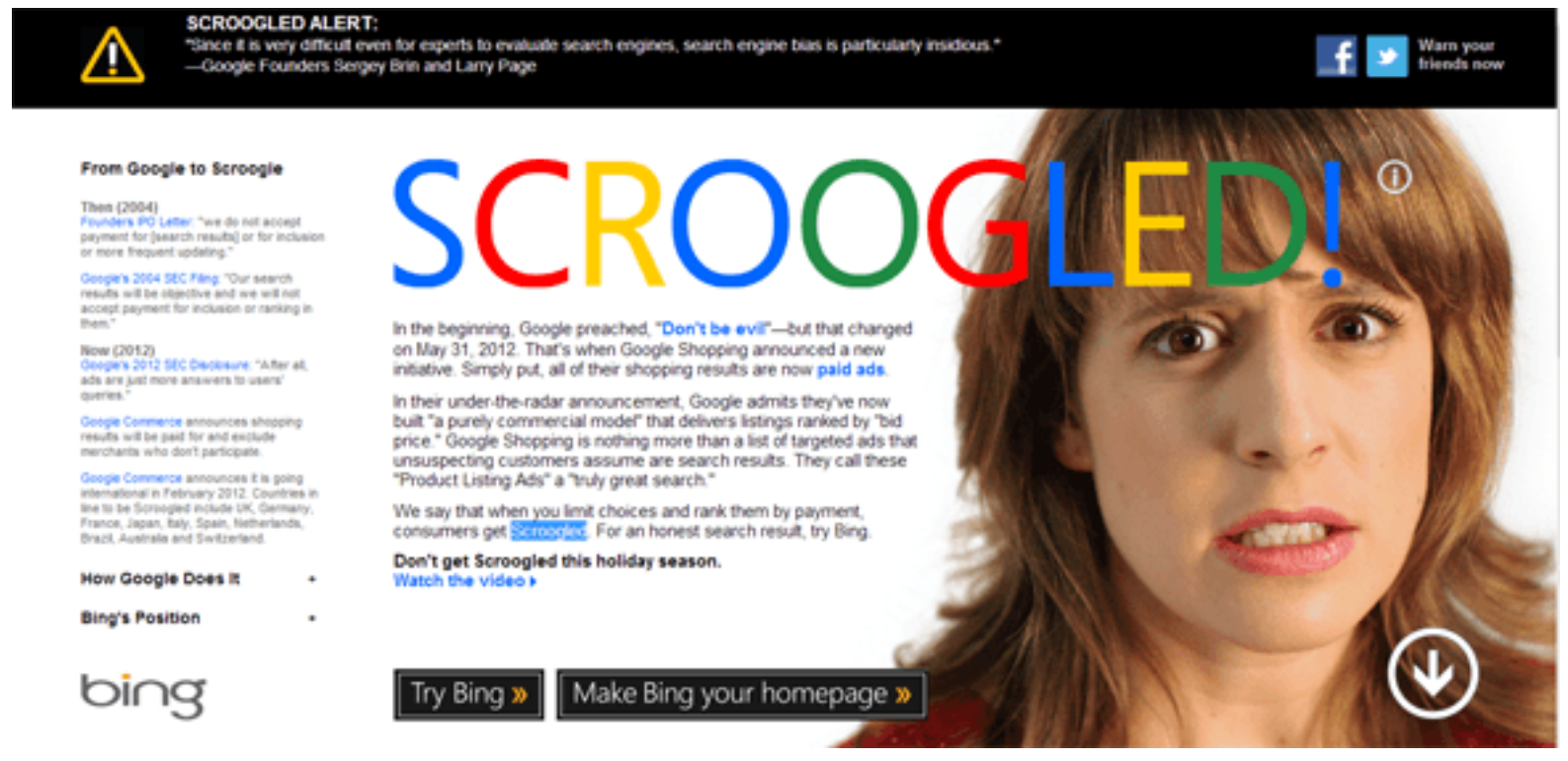

Figure 18. Bing vs Google, 2012

\subsection{Impact of Comparative Advertising on Brand Image and Consumer Perception}

Previous studies tried to demonstrate the effect of comparative advertising on brand image. Thompson investigated the impact of ad format on enhancing the effectiveness of comparative vs noncomparative ads and found out that noncomparative ads are more effective than comparative ads when consumers are exposed to images (Thompson, 2006). Another study found that the introduction of a new brand which shares an attribute with an existing brand or shares the same level of quality with an existing brand will cause that existing brand to be seen as less similar to another existing brand (Baker, 2002). Developing from Beard's study, the effect of comparative advertising on the brand image has been further analyzed and proven that the creation of misleading ads indeed can damage the ad creator's credibility as well as the business rivalry between the brands (Beard, 2010). Similarly, other researches tried to examine the effect of comparative ads on brand commitment and brand attitudes. On his study, Pillai found out that there is a three-way interaction between consumer commitment, attribute typicality and the type of advertisement (Pillai, 2008). If the brand image is not harmed and the brand's endorsement strategies are executed on multiple channels, the comparative advertising is to be found effective (Shih, 2010). In a very recent study, Chauhan investigated the memory recall of comparative advertising and found out that it is way simpler and higher than the noncomparative advertising. Moreover, comparative ads capture the eyeballs as participants chose eight advertisements as the most exciting ads and 5 out of them were the comparative ads (Chauhan, 2016). Comparative advertising's effect heavily depends on the consumer's perceived differentiation and its association with the brand. Recent findings clearly emphasize that the brands use comparative advertising to distinguish one brand from the other one, particularly (Soscia, 2010). Comparative advertising ties comparisons between the advertised brand and its competitors either directly or indirectly. While the use of comparative advertising is commonplace and increasing in today's marketplace, 
advertisers must use comparative advertising cautiously due to regulations and legislations. Comparative advertising is dominantly done by the challenger brand, i.e., the brand which is in the second position and sometimes customers, loyal to the leading brand, are not really interested about what advantages their competitor brand possess. Therefore, marketers need to strategize their comparative efforts to reach the maximum effect. Comparative ads can be a relatively cheap and effective way to gain quick publicity in fiercely completive markets such as airlines and telecom industries. "For some products, competitive advertising helps maintain and develop a competitive market which in many ways is what advertising is all about," says Ian Twinn, director of public affairs at the Incorporated Society of British Advertisers (Marketing Week, 2000).

\section{Research Methodology}

To explore the different types of comparative advertisements, we have selected relevant ads were from renowned brands. For ease of the study, the focus was mainly on print advertisements. This study uses exploratory research methodology to analyze the advertisements as well as a systematic literature review. The study aims critically to examine the lack of limitations of existing legislation, along with the features, definitions and dimensions of comparative advertising in the Middle East region. Exploratory research design does not aim to provide the conclusive results to the research questions. In this method, the researcher merely explores the topic with different angles and tends to tackle a new problem with little or no previous research has been done in the area (Singh, 2007). We used exploratory research due to the lack of both empirical data and the existing literature in the Middle East. The goal of any exploratory research is to explore a problem and not driving a particular conclusion from it. With our research, we aim to open a discussion of having a set of guidelines for the Middle East marketers to start utilizing comparative advertising. Most importantly, utilization of exploratory research will determine us if the topic is worth pursuing further or not.

\section{Comparative Advertising Regulations and Legislations Worldwide}

Research shows that the progressive movement of setting rules for advertising had begun in 1911 through the Associated Advertising Club of America (AACA). In a convention held by the association, the president of AACA had delivered the "Ten Commandments of Advertising" which were of great significance in the history of advertising legislation and comparative advertising, later on, stating:

Thou shall not covet, nor imitate, nor run down thy neighbours' business; Thou shall not covet, nor imitate, nor run down thy neighbours' name, nor his wares, nor his trademark; nor anything that is thy neighbours'.

Direct comparative advertising has been permitted in the U.S. since 1971, the Federal Trade Commission has defined comparative advertising as advertising that compares alternative brands on objectively measurable attributes or price, and identifies the alternative brand by name, illustration or other distinctive information. (ftc.gov/public-statements/1979/08/statement-policy) The policy statement encourages the naming of, or reference to competitors, but requires clarity and disclosure to avoid consumer deception. In 1979, the commission had supported brand comparison where the bases of the comparison are identified, considering it as a useful tool and source of information that assists consumers in making rational purchase decisions. The American Association of Advertising Agencies (AAAA) had set specific rules and regulations for comparative advertising (Belch \& Belch, 2001, p. 732):

1) The intent and connotation of the ad should be to inform and never to discredit or unfairly attack competitors, competing for products or services.

2) When a competitive product is named, it should be one that exists in the marketplace as significant competition.

3) The competition should be fairly and properly identified but never in a manner or tone of voice that degrades the competitive product or service.

4) The advertising should compare related or similar properties or ingredients of the product, dimension, feature to feature.

5) The identification should be for honest comparison purposes and not simply to upgrade by association.

6) If a competitive test is conducted, it should be done by an objective testing source, preferably an independent, so that there will be no doubt as to the veracity of the test.

7) In all cases, the test should be supportive of all claims made in the advertising that is based on the test.

8) The advertising should never use partial results or stress insignificant differences to cause the consumer to draw an improper conclusion. 
9) The property being compared should be significant in terms of value or usefulness of the product to the consumer.

10) Comparatives delivered through the use of testimonials should not imply that the testimonial is more than one individual's thought unless that individual represents a sample of the majority viewpoint.

The EU Misleading and Comparative Advertising Directive and EU Legislators consider comparative advertising of high potential benefits to the consumers in terms of stimulating competition between products and services. Having a set of rules, that are similar to the regulations of the AAAA, that any comparative ad needs to follow to be lawful, these set of rules are identical and followed by the $28 \mathrm{EU}$ member states:

1) It must not be misleading.

2) It must compare like-for-like products or services.

3) It must objectively compare material, relevant, verifiable and representative features of the goods or services.

4) It must not denigrate the trademarks, trade names, goods, services or activities of a competitor.

5) It must not take unfair advantage of a trademark, trade name or other distinguishing marks of a competitor.

Canada, Malaysia, India, and South Africa, have all allowed the use of comparative advertising, considering it a creative advertising technique which allows the consumers to see the product's superiority over its' competitors, promoting a better environment for competition. Several rules have been set in each of the mentioned countries to regulate the use of comparative advertising quite similar to the ones set by AAAA and EU, where they state that comparisons must be based on a factual and fair basis, transparent and supported by evidence, must not disparage or attack the competitor, or exaggerate the importance and nature of the compared features. Based on the AANA Code of Ethics and the Australian Consumer Law states that "there is no specific prohibition against comparative advertising under Australian law, but such advertising will be subject to the general prohibition on misleading and deceptive conduct and false and misleading representations contained in the Australian Consumer Law (Schedule 2 to the Competition and Consumer Act 2010 (Cth)). There are also provisions under the AANA Code of Ethics which provide that certain advertising must not be misleading or deceptive (or likely to mislead or deceive) or contain a misrepresentation, which is likely to cause damage to the business or goodwill of a competitor." (http://aana.com.au)

\section{Comparative Advertising Regulations and Legislations in the Middle East}

While Egypt is known to be the hub of advertising in the Middle East, no regulations have been set for comparative advertising. As for the United Arab Emirates, there is no law regulating comparative advertising; hence, the UAE law presumes that all forms of advertising are permitted. While the provisions of the Federal Law, 1992, No. 37 prohibits the unlawful use of a registered trademark, yet, there is no specific stipulation as to the fair use of competitor's name or trademark. No laws or regulations were explicitly set for comparative advertising in the Middle East and MENA region. In the UAE, there are no specific legislations on comparative advertising. Furthermore, arguments of free competition may suggest that one should be permitted to use another's mark if the use of such mark is for merely descriptive purposes. On the other hand, the provisions of Federal Law No. 37 for the year 1992 concerning trademarks (as amended; "UAE Trademark Law") prohibit unlawful use of a registered trademark. In a broader scheme, therefore, it can be argued that using a competitor's trademark to compare similar products merely could be interpreted as unlawful use; thus, exposing the entity to liability for unauthorized use of another's trademark. Further adding ambiguity to the debate is the fact that the UAE Trademark Law does not contain a specific provision as to the fair use principle (Hijazin, 2014). Therefore, it is crucially important to address this gap in advertising.

\section{Proposed Regulations and Legislations for the Middle East}

Based on the conducted research, standards for comparative advertising have been concluded by the researchers to set the criteria for the implementation of comparative advertising in the MENA region:

- The main aim of the comparative ads is to introduce consumers the advantages of the product in comparison to the competitors, never to degrade competitor.

- Introduce the competitor in a decent and seemly form: do not use wordings that underestimate the competitor.

- The comparison should be based on precise features (ingredients, price, easiness of use, .); comparative 
ads should not generally state that a product is better than a competitor.

- While the main aim of the comparison is to inform, compared features should be of significance to the consumers in terms of value and usefulness, as comparing insignificant features leads to irrelevant discrepancy among consumers.

- The comparison should be based on the culture's ethical and legal standards and social norms.

- An objective trusted testing source for comparative tests is a must, to support claims mentioned in the ads concerning compared features that are based on tests.

- Testimonials of individuals should state if it is an individual testimony, or if this individual represents a sample of majority consumers.

- Specific provisions are to be added to the rules and regulations of advertising for the proper and fair use of comparative advertising.

\section{Limitations and Future Research}

The present study has potential limitations. First of all, the lack of previous studies and the samples in the Middle East region presents a challenge for comparison. Extensive research can be carried out with proper data set and comparative content analysis. A particular focus on digital advertisements appears to be desirable for future research. The second limitation of the study is the lack of empirical data. It is recommended to experiment with traditional and digital ads to strengthen the arguments of the conclusions.

Future research can also examine the generational differences in comparative advertising effectiveness such as Gen X, Millennials and Gen Z. This line of research could provide policymakers, marketers and content strategist with a keen edge while devising their communication plan.

\section{References}

AANA Regulations. (2019). Retrieved from https://aana.com.au/

Advertising by Philip H. (n.d.). Dougherty. Retrieved from https://www.nytimes.com/1977/12/23/archives/advertising-marsteller-thinking-and-renault-sales.html

Baker, T. L., Hunt, J. B., \& Scribner, L. L. (2002). The effect of introducing a new brand on consumer perceptions of current brand similarity: The roles of product knowledge and involvement. Journal of Marketing Theory and Practice, 10(4), 45-57. https://doi.org/10.1080/10696679.2002.11501925

Beard, F. (2008). Negative comparative advertising: When marketers attack. In Marketing Metaphors and Metamorphosis (pp. 146-161). London: Palgrave Macmillan. https://doi.org/10.1057/9780230227538_10

Beard, F. (2010). Comparative Advertising Wars: An Historical Analysis of Their Causes and Consequences. Journal of Macromarketing, 30(3), 270-286. https://doi.org/10.1177/0276146710372222

Chauhan, G. S., \& Shukla, T. (2016). Consumer psychology and memory recall effect: An analytical study on comparative advertising. Learning Community-An International Journal of Educational and Social Development, 7(1), 77-93. https://doi.org/10.5958/2231-458X.2016.00009.9

Emma, M. (2020, February 21). from https://www.thedrum.com/news/2020/02/21/the-best-burger-king-ads-burned-its-rivals

Harmon, R. R., Razzouk, N. Y., \& Stern, B. L. (1983). The information content of comparative magazine advertisements. Journal of Advertising, 12(4), 10-19. https://doi.org/10.1080/00913367.1983.10672858

Hijazin. (2014). Retrieved from https://www.tamimi.com/law-update-articles/comparative-advertising-in-the-uae-a-legal-perspective/

Krippendorff, K. (2004). Reliability in content analysis: Some common misconceptions and recommendations. Human Communication Research, 30(3), 411-433. https://doi.org/10.1111/j.1468-2958.2004.tb00738.x

Marketing Week. (2000). Ryanair ad victory sounds a battlecry. Retrieved from https://www.marketingweek.com/ryanair-ad-victory-sounds-a-battlecry/

Mueller, W. (2004). The Revival of Economics at the FTC in the 1960s. Review of Industrial Organization, 25(1), 91-105. https://doi.org/10.1023/B:REIO.0000040548.70602.b5

Phung, P. (2019). Comparative Advertising - A deadly marketing tactic in the competition. Seinäjoki University of Applied Sciences. Winter 2019 School of Business and Culture.

Pillai, K. G., \& Goldsmith, R. E. (2008). How brand attribute typicality and consumer commitment moderate the 
influence of comparative advertising. Journal of Business Research, 61(9), 933-941. https://doi.org/10.1016/j.jbusres.2007.10.002

Romano, C. (2005). Comparative Advertising in the United States and in France. Northwestern Journal of International Law and Business, 25, 371.

Shih, T. Y. (2010). Comparative Analysis of Marketing Strategies for Manufacturers 'and Retailers' brands. International Journal of Electronic Business Management, 8(1).

Shona, G. (2019, January 7). 7rom https://www.businessinsider.sg/apple-google-ad-ces-2019-privacy-imessage-2019-1

Singh, K. (2007). Quantitative Social Research Methods (p. 64). SAGE Publications. https://doi.org/10.4135/9789351507741

Soscia, I., Girolamo, S., \& Busacca, B. (2010). The effect of comparative advertising on consumer perceptions: Similarity or differentiation? Journal of Business and Psychology, 25(1), 109-118. https://doi.org/10.1007/s10869-009-9130-4

Thompson, D. V., \& Hamilton, R. W. (2006). The effects of information processing mode on consumers' responses to comparative advertising. Journal of Consumer Research, 32(4), 530-540. https://doi.org/10.1086/500483

Williams, K. C., \& Page, R. (2013). Comparative Advertising as a Competitive Tool. Journal of Marketing Development and Competitiveness, 16, 5-16.

\section{Copyrights}

Copyright for this article is retained by the author, with first publication rights granted to the journal.

This is an open-access article distributed under the terms and conditions of the Creative Commons Attribution license (http://creativecommons.org/licenses/by/4.0/). 